
\title{
Effects of Spirulina in Lead Induced Toxicities in Long Evans Rats
}

\author{
M. A. Rahman, N. F. Moitry, M. Alam, Z. Yasmin, D. Debnath and M. Mostofa
}

Department of Pharmacology, Bangladesh Agricultural University, Mymensingh

\begin{abstract}
The effect of spirulina in lead induce toxicity was conducted on 20 adult rats (Long Evans). Rats were randomly divided into four equal groups and subjected to treatments once daily for a period of 4 weeks. Rats treated with lead acetate showed severe toxic and significantly reduced erythrocytes count, hemoglobin content and significantly elevated SGPT, SGOT and ALP. Rats treated with lead acetate plus spirulina in two doses, $1500 \mathrm{mg} / \mathrm{kg}$ and $2000 \mathrm{mg} / \mathrm{kg} \mathrm{b}$.wt. were apparently normal. There hematological and biochemical parameters were not altered significantly. This experiment revealed that treatment with spirulina was effective in lead-induced toxicity and to restore altered values of hematological and biochemical parameters.
\end{abstract}

Keywords: Induced, Lead, Rats, Spirulina

\section{Introduction}

Spirulina is well-known in many areas in the world as a food source for both animals and humans, spirulina can add minerals, proteins, and vitamins to the diet. It contains antioxidants such as beta carotene and zeaxanthin. Spirulina may increase the production of immuno-stimulatory and immuno-modulator chemicals known as interferons and interleukins (Pugh et al, 2001). Mankind has been using lead for over 6000 years, and solely as a result of anthropogenic activities lead has become the most ubiquitous toxic metal. Hippocrates was probably the first of ancients to recognize lead as the cause of colic. Lead toxicity was recognized and recorded as early as $2000 \mathrm{BC}$ and its wide spread use has been a cause of endemic chronic plumbism in several societies throughout history. With the industrial expansion in the last two centuries the problem has become more serious, as evident from the Antarctic and Arctic ice core data showing presence of lead in such far off places. The last three centuries also witnessed the worst outbreak of lead poisoning among adult which were occupational in origin, although environmental pollution also reported adverse effect of lead on health (Jaffery, 2000).

Many reviews and references are available in literature related with health effects of exposure to lead (Parikh, 1990; Needleman HL, 1990). Lead poisoning in developing countries is a serious problem (Romieu et al, 1997; Krinaswamy K and Kumar BD,1998). Without proper corrective action, $\mathrm{Pb}$ exposure would remain a threat to many generations in the developing world. Simultaneous administration of spirulina and lead reduces levels of lipid peroxidation products. Levels of lipid peroxidation such as melanodialdehyde, conjugated diene and hydroperoxide were measured in liver, lung, and kidney of treated rats (Upasani and
Balaraman, 2001). Spirulina has a significant effect on scavenging free radicals, thereby protecting the organs from damage caused by the exposure to lead. Further more, spirulina shows a significant $(\mathrm{p}<0.05)$ decrease in the deposition of lead in the brain. (Upasani and Balaraman, 2003).

Bangladesh is an environmentally polluted country. Both of human being and animals are affecting with environmental pollutants. Possible positive effect of spirulina on lead induce has been studied for the first time in this region, so the present research work has been carried out to know the effects of spirulina in induced lead toxicity in rats.

\section{Metarials and Methods}

The studies were conducted on 20 rats (Long Evans), 145-170 g maintained on standard pellet diet and drinking water adlibitum. The rats were collected from the Department of Pharmacology, Bangabandhu Sheikh Mujib Medical University (BSMMU), Dhaka. All the rats were kept under close observation in order to maintain good health for conducting experiment properly for a period of seven days. The laboratory was well ventilated with relative humidity of 70$80 \%$. The room lighting consisted of alternate 12 hours light and dark periods.

Rats were randomly divided into four equal groups $(5 \times 4)$, each group comprising of five rats and were marked as group A, B, C, and D.

$>$ Group A- No treatment was given, given normal feed and water as per requirement;

$>$ Group B- Lead acetate $20 \mathrm{mg} / \mathrm{kg}$ body weight with $4 \mathrm{ml}$ distilled water

> Group C- Lead acetate $20 \mathrm{mg} / \mathrm{kg}$ body weight plus spirulina $1,500 \mathrm{mg} / \mathrm{kg}$ b. wt. with $4 \mathrm{ml}$ distilled water.

$>$ Group-D Lead acetate $20 \mathrm{mg} / \mathrm{kg}$ body weight plus spirulina $2,000 \mathrm{mg} / \mathrm{kg} \mathrm{b}$. wt. with $4 \mathrm{ml}$ distilled water.. 
Body weight were taken before starting of experiment and at 14 days interval during 28 days of feeding period.Blood samples were collected just before treatment, day 14 and day 28 of treatment from tail and heart of the control and treated diethylanesthetized rats. The hematological parameters were determined as per method cited by Lamberg and Rothstein (1977). Following biochemical parameters were studied:

(a) Serum Glutamate oxaloacetate transaminase (SGOT)/ Asparate transaminase AST.

(b) Serum glutamate pyruvate transaminase (SGOT)/ Alanine transaminase ALT.

(c) Alkaline phosphatase (ALP).

Determination of SGPT/ALT by using Reflotron ${ }^{\circledR}$ (Boehringer) Mannheim)

Required amount of blood was drawn with capillary pipette up to the red mark of the pipette $(30 \mu / 1)$. Citrated anticoagulant was used. Then one (01) drop of blood i.e. blood within the pipette was placed to the centre of the red application zone (xx) of the GPT test strip after opening the sliding cover of the test strip. The enzyme activity was shown for $37^{\circ} \mathrm{C}$ in $\mathrm{u} / \mathrm{I}$.

Determination of SGOT/AST using Reflotron ${ }^{\circledR}$ plus (Bochringer Mannheim): Required amount of blood was taken with capillary pipette up to red mark $(30 \mu \mathrm{l})$ and was placed as a drop to the centre of red application 2 one $(\mathrm{xx})$ of the GOT test strip after removing the outer coverings of the test strip.

After opening the sliding cover of the machine the test strip was placed on to the guide within 15 second and the test strip was forwarded until it locks into place. The sliding cover was closed properly. The GOT level of displayed on the monitor automatically after 1-2 minutes. The enzyme activity was shown for $37^{\circ} \mathrm{C}$ in $\mathrm{u} / \mathrm{l}$

Determination of ALP using Reflotron ${ }^{\circledR}$ (Boehrinyer Mannheim)

After opening the sliding cover of the machine the test strip was placed on to the guide within 15 seconds and the test strip was forwarded until it locks into place. Then the sliding cover of the machine was closed and waited for result. The ALP level was displayed on the monitory within to 2 minutes. The enzyme activity was shown for $37^{\circ} \mathrm{C}$ in $\mathrm{U} / \mathrm{I}$

At the end of the experimental period i.e. 28 days of treatment period, all the rats were sacrificed and were dissected for observing the postmortem changes.

The different tissues and organs (blood, liver, kidney, brain and femur) were collected after grinding and mixing with normal saline "Merck Lead Test" kit was done for determination of lead in tissue.

\section{Result and Discussion}

The experiment was carried out to observe the effects of spirulina and lead acetate on toxic signs and body weight, some hematological (TEC and $\mathrm{Hb}$ Content) and some biochemical parameters (SGPT/ALT, SGOT/AST and ALP), postmortem changes and to determine of lead in different organs of the body in rats.

Toxic sign In Group-A all of the rats were almost normal. Rats of Group-B show toxic sign in $2^{\text {nd }}$ week like anxiety, loss of muscle coordination, tremor, dizziness, fatigue, posterior paralysis, ruffled hair coat and marked weight loss.

Rats of Group-C show toxic sign in $3^{\text {rd }}$ week, rats showed mild toxic sings i.e. loss of appetite, ruffled hair coat, salivation, ataxia and in coordination.

Rats of Group-D show toxic sign in $3^{\text {rd }}$ week of treatment all the rats showed slight toxic sings i.e. anorexia, idle sitting, salivation and ruffled hair coat.

Toxic symptoms observed in present experiment due to lead acetate administration were almost similar to the finding of Haque (2005). Higher dose of spirulina (2000 mg/kg b. wt) was found to be better effective than lower dose $(1500 \mathrm{mg} / \mathrm{kg} \mathrm{b}$. wt). Now a days many scientists reported that spirulina was found to be effective for reducing the arsenic toxicity in the body (Misbahuddin et al., 2006) The exact mechnism of reducing toxicity by spirulina is not known.

\section{Effect of body weight}

The mean body weight of rats of group-B was significantly $(\mathrm{p}<0.01)$ reduced, but in group-C and group-D, body weights were slightly my be due to protective effect of spirulina against lead toxicity in rat (Upasani and Balaraman, 2003). The reduction of body weight in group-B might be due to the interruption in absorption and metabolism of feed nutrients essential for health (Marija, et al. 2004).

Total erythrocytes count (TEC).

In group- $\boldsymbol{A}$ (control) TEC was almost normal. In group-B, TEC was significantly decreased $(\mathrm{P}<0.01)$ on day 14 and 28 of treatment. In group-C and $\mathrm{D}$ TEC were not altered significantly. The reduction of total erythrocyte count might be due to the depressing effects of lead acetate on the hematopoietic organs of the body or might adversely affect the RBC in the body during continuous administration of lead acetate orally 


\section{J. Environ. Sci. \& Natural Resources, 5(1): 79 - 82, 2012}

\section{Hemoglobin (Hb) content}

Rats of group-A, exhibited normal $\mathrm{Hb}$ content. In group- $\mathrm{B} \mathrm{Hb}$ content was significantly decreased $(\mathrm{P}<0.01)$ on day 14 and 28 of treatment. In group-C and $\mathrm{D} \mathrm{Hb}$ contents were not significantly reduced The reduction of hemoglobin content might be due to the depressing effects of lead acetate on the hematopoietic organs of the body or might adversely affect the RBC in the body during continuous administration of lead acetate orally Biochemical parameters (SGPT, SGOT and ALP). The activities of SGOT, SGPT and ALP were significantly elevated in group-B. In group-C and D the elevation of SGPT, SGOT and ALP were less than that of group-B. In the group-A and B the toxic effects were mild because spirulina has protective role against lead toxicity. These findings are similar to that of Upasani and Balaraman(2001).

Table 1. Pre and Post experimental body weight and hemato-biochemical values in rats.

\begin{tabular}{|c|c|c|c|c|}
\hline Groups & Parameters & Pre treatment & $\begin{array}{c}\text { Post treatment } \\
\text { Day } 14\end{array}$ & $\begin{array}{l}\text { Post treatment } \\
\text { Day } 28\end{array}$ \\
\hline \multirow{6}{*}{ A( Normal Control) } & Body weight (gm) & $143.42 \pm 2.1$ & $144.21 \pm 1.8$ & $144.25 \pm 1.7$ \\
\hline & TEC (million/ml) & $6.54 \pm 0.12$ & $6.70 \pm 0.09$ & $7.41 \pm 0.11$ \\
\hline & $\mathrm{Hb}(\mathrm{gm} \%)$ & $11.50 \pm 0.04$ & $12.30 \pm 0.03$ & $12.50 \pm 0.01$ \\
\hline & SGPT/ALT (U/L) & $58.34 \pm 1.39$ & $60.59 \pm 1.5$ & $62.92 \pm 1.43$ \\
\hline & SGOT/AST (U/L) & $148.53 \pm 3.20$ & $153.59 \pm 2.91$ & $160.73 \pm 3.10$ \\
\hline & $\operatorname{ALP}(\mathrm{U} / \mathrm{L})$ & $1.52 . \pm 0.2$ & $1.51 \pm 0.2$ & $1.5184 \pm 0.20$ \\
\hline \multirow{6}{*}{$\begin{array}{c}\text { B (Lead acetate @ } 20 \\
\mathrm{mg} / \mathrm{kg} \mathrm{b} . \mathrm{wt})\end{array}$} & Body weight (gm) & $146.3 \pm 2.43$ & $128.23 \pm 2.2$ & $105.12 \pm 1.83$ \\
\hline & TEC (million/ml) & $6.98 \pm 0.07$ & $5.59 \pm 0.06$ & $4.98 \pm 0.04$ \\
\hline & $\mathrm{Hb}(\mathrm{gm} \%)$ & $12.90 \pm 0.03$ & $11.50 \pm 0.02$ & $09.90 \pm 0.01$ \\
\hline & SGPT/ALT (U/L) & $61.29 \pm 1.23$ & $85.38 \pm 1.19^{*}$ & $116.12 \pm 1.7^{*}$ \\
\hline & SGOT/AST (U/L) & $145.85 \pm 2.94$ & $182.92 \pm 3.2 *$ & $225.79 \pm 3.15 *(41 \%)$ \\
\hline & ALP (U/L) & $1.50 \pm 0.54$ & $1.85 \pm 0.20^{*}$ & $2.43 \pm 0.10 *(44 \%)$ \\
\hline \multirow{6}{*}{$\begin{array}{l}\text { C (Lead acetate @ } 20 \\
\text { mg/kg b.wt plus } \\
\text { spirulina @ } 1500 \\
\text { mg/kg.b.wt.) }\end{array}$} & Body weight (gm) & $157.21 \pm 2.1$ & $158.10 \pm 1.9$ & $160.23 \pm 1.93$ \\
\hline & TEC (million/ml) & $7.10 \pm 0.08$ & $7.00 \pm 0.09$ & $7.13 \pm 0.12$ \\
\hline & $\mathrm{Hb}(\mathrm{gm} \%)$ & $11.50 \pm 0.04$ & $11.30 \pm 0.05$ & $11.20 \pm 0.03$ \\
\hline & SGPT/ALT (U/L) & $59.12 \pm 1.32$ & $67.36 \pm 1.23$ & $75.29 \pm 1.42(20 \%)$ \\
\hline & SGOT/AST (U/L ) & $147.70 \pm 3.20$ & $159 \pm 3.29$ & $170.61 \pm 3.01$ \\
\hline & $\mathrm{ALP}(\mathrm{U} / \mathrm{L})$ & $1.49 \pm 0.94$ & $1.63 \pm 0.89$ & $1.80 \pm 0.59$ \\
\hline \multirow{6}{*}{$\begin{array}{l}\text { D (Lead acetate @ } 20 \\
\text { mg/kg b.wt plus } \\
\text { spirulina @ } 2000 \\
\text { mg/kg b.wt.) }\end{array}$} & Body weight (gm) & $163.67 \pm 1.92$ & $168.24 \pm 1.8$ & $170.2 \pm 1.7$ \\
\hline & TEC (million/ml) & $6.93 \pm 0.09$ & $7.01 \pm 0.11$ & $7.23 \pm 0.09$ \\
\hline & $\mathrm{Hb}(\mathrm{gm} \%)$ & $12.67 \pm 0.06$ & $11.80 \pm 0.05$ & $12.00 \pm 0.04$ \\
\hline & SGPT/ALT (U/L) & $60.02 \pm 1.25$ & $66.04 \pm 1.7$ & $71.12 \pm 1.62$ \\
\hline & SGOT/AST (U/L ) & $143.69 \pm 3.53$ & $155.72 \pm 3.20$ & $162.62 \pm 2.92$ \\
\hline & $\mathrm{ALP}(\mathrm{U} / \mathrm{L})$ & $151.35 \pm 3.72$ & $159.93 \pm 3.40$ & $170.53 \pm 3.2$ \\
\hline
\end{tabular}

* Significantly decreased $(\mathrm{P}<0.01)$ 


\section{Conclusions}

In this study it is concluded that the treatment with spirulina was effective in lead-induced toxicity and to restore altered values of hematological and biochemical parametwrs and in mobilizing lead deposition in tissues. However, higher dose of spirulina was more effective in rat. Further extensive studies are needed to use spirulina as a economic therapy in lead poisoning.

\section{References}

Jaffery, F. N. 2001. Current status of lead poisonig in India. http//www.leadpoisoning.net

Khan, A. Q. 1989. Epidemiology and diseas control. $1^{\text {st }}$ Ed.World university Service Press, Dhaka University Campus, Nilkhet, Dhaka.

Krishnaswamy, K. and Kumar, B. D. 1998. Lead toxicity. Ind. Pediatr. 35: 209-216.

Lamberg, S. L and Rothstein, R. 1977. Laboratory Manual of Hematology and Urinalysis. Avi. Publishing Company, Inc, Westport Connecticut, U.S.S.R.

Marija, V.; Piasek, M.; Blanusa, M.; matek Saric. M.; Juresa, D. and Kostial. K. 2004. Succimer treatment and calcium supplimentation reduce tissue lead in suckling rats. J. Appl.Toxicol. 24(2): 123-128.

Mir, M.; Islam, A. Z. M.; Salamat, K.; Ifthaker, A. M.; Nazrul, I. and Anjumanara 2006. Efficacy of spirulina extract plus zinc in patients of hronic arsenic poisoning: a randomized placebocontrolled study. (Risk factors). Journal of Toxicology: Clinical Toxicology. 44.2: p135 (7).

Needdleman, H. L. 1990. History of lead poisoning in the world. In: Lead poisoning prevention and treatment: Implementing a national programme in developing countries. February 8-10, Bangladesh, India. Proceedings of the International Conference on Lead Poisoning Prevention and Treatment, pp. 17-25.

Parikh, D. J. 1990. Human exposure assessment to lead, an overview in India. Ind.J. Indust.Med.36:63-75.

Pugh, N.; S.A. Ross, H.N. Elsohly and D.S. Pasco. 2001. Isolation of thre3ee weight polysaccharide preparation with potent immunostimulatory activity from Spirulina platensis, Aphanizomenon flos-aque and Chorella pyrenoidosa. Planta Med, 67:737-742

Romieu, I; Lacasann, M. and McConnel, R. 1997. Lead exposure in Latin America and the Caribbean. Environ. Health Perspect. 105: 398405.

Upasani, C.D. and Balaraman. 2001. Effect of vitamin $\mathrm{E}$, vitamin $\mathrm{C}$ and spirulina on the levels of membrane bound enzymes and lipids in some organs of rats exposed to lead. Indian Journal of Pharmacology, 33: 3, 185-191; 34.

Upasani, C.D. and Balaraman. 2003. Protective effect of spirulina on lead induced deleterious changes in the lipid peroxidation and endogenous antioxidants in rats. Phytotherapy-Research, 17: 4, pp 330-334; 2 